$\begin{array}{ll} & \text { Etnográfica } \\ \text { etnográfica } & \text { Revista do Centro em Rede de Investigação em }\end{array}$

Antropologia

vol. 25 (2) | 2021

Vol. 25 (2)

\title{
Militancia y estéticas políticas en la ciudad neoliberal
}

Activism and political aesthetics in the neoliberal city

\section{Dolores Señorans}

\section{(2) OpenEdition \\ Journals}

Edición electrónica

URL: https://journals.openedition.org/etnografica/10100

DOI: 10.4000/etnografica.10100

ISSN: 2182-2891

\section{Editor}

Centro em Rede de Investigação em Antropologia

Edición impresa

Paginación: 405-427

ISSN: 0873-6561

\section{Referencia electrónica}

Dolores Señorans, «Militancia y estéticas políticas en la ciudad neoliberal», Etnográfica [En línea], vol. 25 (2) | 2021, Publicado el 29 julio 2021, consultado el 19 enero 2022. URL: http://

journals.openedition.org/etnografica/10100 ; DOI: https://doi.org/10.4000/etnografica.10100

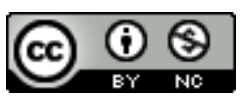

Etnográfica is licensed under a Creative Commons Attribution-NonCommercial 4.0 International License. 


\section{Militancia y estéticas políticas en la ciudad neoliberal}

\section{Dolores Señorans}

Este artículo analiza el desarrollo de formas de militancia en articulación con cómo se experimenta y produce el espacio urbano en el barrio de La Boca, Ciudad Autónoma de Buenos Aires, Argentina. Muestro que el Estado y los desarrolladores privados transformaron el espacio barrial apoyándose en la estética de ciertas prácticas populares para visibilizar espacios y sentidos de comunidad orientados al turismo, al tiempo que ocultaron otros sujetos, prácticas y formas de vida. Paralelamente, despliego el modo en que la Organización Social y Política Los Pibes, junto a otras organizaciones y militantes barriales, disputaron este reparto de lo sensible desde prácticas de militancia y formas de intervención estética en el espacio urbano. Sostengo que las estéticas fueron tanto un modo de conocimiento como de producción de geografías políticas que pusieron en cuestión las configuraciones espaciales de la desigualdad en la ciudad neoliberal.

PALAVRAS CLAVES: militancia, estéticas, disputas espaciales, procesos de renovación urbana.

Activism and political aesthetics in the neoliberal city - This article analyses the development of forms of activism in articulation with the ways in which urban space is experimented and produced in the neighbourhood of La Boca, Buenos Aires, Argentina. I show that the State and private developers transformed this space based on the aesthetic quality of certain popular practices to make visible some areas and to promote ideas of community oriented to tourism; while other subjects, practices and forms of life were concealed. At the same time, I show how the social and political organisation Los Pibes, together with other neighbourhood based activists and organisations, sought to transform this distribution of the sensible through practices of activism and aesthetic interventions on urban space. I contend that aesthetics was a form of knowledge and also a way of producing political geographies that put into question the spatial configurations of inequality in the neoliberal city.

KEYWORDS: activism, aesthetics, spatial disputes, urban renewal processes.

SEÑORANS, Dolores (dolisenorans@gmail.com) - British Academy Newton International, Universidad de Cambridge, Inglaterra. 


\section{INTRODUCCIÓN}

En junio de 2013 visité por primera a la organización Los Pibes en el barrio porteño de La Boca. En ese entonces estaba iniciando mi doctorado y llegué interesada por analizar el modo en que organizaciones políticas desarrollaban iniciativas laborales en el marco de la implementación de un conjunto de políticas públicas orientadas a la generación de empleo a través de la creación de cooperativas de trabajo. Por la mañana me recibió Lionel, uno de los fundadores de esta organización que nació como un comedor infantil hacia 1996. El primer lugar que visitamos fue la Unidad de Producción Social, el edifico donde funcionaban varias de las cooperativas o "emprendimientos" de la organización, entre ellas una radio comunitaria, un centro de formación en oficios y una cooperativa textil. Sin embargo, otro espacio ocupó un momento destacado en aquella visita: al edificio de la Cooperativa de Vivienda Los Pibes (Covilpi). ${ }^{1}$

Hacia el mediodía nos dirigimos hasta la obra todavía en construcción. Acompañados de Pilar, una de las cooperativistas, recorrimos el edificio - hoy terminado - pasando por algunos de sus 33 departamentos de tres ambientes con un baño, cocina integrada, lavadero y balcón o patio. Subimos hasta el cuarto y último piso para apreciar la vista. Desde allí Lionel me señaló una serie de puntos claves para comprender la geografía barrial: Sancheti - un conventillo construido al interior de una antigua fábrica de calzados -, el puente Nicolás Avellaneda, y la villa del bajo autopista. Tanto por la altura como por la ubicación del edificio, desde allí se ofrecía una perspectiva particular sobre ese espacio, sobre lo que se muestra y lo que se oculta. En efecto, esos puntos señalados no forman parte de la imagen más difundida del barrio de La Boca en la que suelen destacarse zonas o lugares visitados por el turismo. Sin embargo, todos estos sitios mostraban la configuración de la desigualdad en el barrio. A continuación, Lionel me relató una multiplicidad de acciones que desarrollaron desde mediados de los años 90 como parte de su lucha por la vivienda digna.

Tal como señalaron numerosos estudios, en la década del 90 se desencadenó el proceso de gentrificación y renovación urbana en distintas zonas de la Ciudad Autónoma de Buenos Aires, Argentina (Carman 2006; Girola, Yacovino y Laborde 2011). La Boca fue un caso paradigmático de estas transformaciones que llevaron a la reducción de su histórica disponibilidad de formas de vivienda popular tales como conventillos y pensiones. ${ }^{2}$ En este contexto se conformaron

I Utilizo comillas para citar el discurso directo de mis interlocutores o de los autores consultados y cursiva para categorías sociales. He decidido utilizar el nombre real de la organización en función del acuerdo establecido con quienes la integran. En cambio, los nombres propios de las personas, exceptuando a aquellos que son figuras públicas, han sido modificados para respetar la confidencialidad.

2 Los conventillos - también llamados inquilinatos - son un tipo particular de vivienda popular urbana que se desarrolló hacia fines del siglo XIX y comienzos del siglo XX en ciudades del Cono Sur como Uruguay, Chile y Argentina. Albergaban en sus orígenes a inmigrantes que alquilaban una [continua] 
una diversidad de organizaciones y espacios de articulación que promovieron la lucha por la vivienda digna en el barrio. En este artículo analizo, a partir del caso de la organización Los Pibes, el modo en que se desarrollaron estas formas de militancia en articulación con cómo se experimenta, produce y disputa el espacio urbano. Quiero mostrar que el espacio social y urbano modeló las formas de militancia y que, al mismo tiempo, los procesos de organización se espacializaron transformando el espacio urbano e inscribiendo sentidos desde historias personales y colectivas. Entiendo a la militancia como la producción de sujetos individuales y colectivos a partir de la noción de "hacer juntos/as" (Fernández Álvarez 2016). Esta categoría permite analizar las prácticas políticas colectivas atendiendo particularmente a aquello que se produce en el "transcurrir" y que de manera contingente e inestable toma la forma de proyectos o materialidades concretas, siempre en el marco de relaciones de hegemonía (2016). En particular, propongo reflexionar en torno a la experiencia y la disputa por el espacio urbano retomando la noción de estética propuesta por J. Rancière (2014) en tanto "reparto de lo sensible", esto es, como delimitación de lo visible y lo invisible, de la palabra y el ruido, que definen aquello que está en juego en la política como forma de experiencia. Desde esta perspectiva, sostengo que las estéticas fueron tanto un modo de conocimiento como de producción del espacio y de creación de geografías políticas que pusieron en cuestión las configuraciones espaciales de la desigualdad en la ciudad neoliberal.

Este artículo recupera los resultados de mi investigación doctoral sobre prácticas de militancia y organización colectiva en la economía popular en el área metropolitana de Buenos Aires. El trabajo de campo junto a la organización Los Pibes fue desarrollado entre mayo de 2013 y octubre de $2016 .^{3}$ Durante ese tiempo, realicé observación participante en los espacios cotidianos de interacción entre quienes integran esta organización. Acompañé sus jornadas de trabajo y militancia, asambleas y reuniones, protestas y actividades especiales junto a otras organizaciones o funcionarios estatales. A su vez, reconstruí la historia de la organización a través de conversaciones informales y de

habitación como residencia de familias enteras y compartían los servicios disponibles en espacios comunes como letrinas y duchas. Cabe destacar que en países como Colombia, México y Brasil existen viviendas populares semejantes, aunque tomaron otras denominaciones.

3 Dicha investigación fue posible gracias al financiamiento de una beca doctoral del Consejo Nacional de Investigaciones Científicas y Técnicas (CONICET). Por su parte, la escritura del artículo se realizó en el marco de una beca postdoctoral del CONICET con lugar de trabajo en el Instituto de Ciencias Antropológicas, Facultad de Filosofía y Letras, Universidad de Buenos Aires, Argentina. Asimismo, mi trabajo de modo más general se inscribió en una línea de investigación desarrollada por el equipo del que formo parte en la Universidad de Buenos Aires, dirigido por la Dra. María Inés Fernández Álvarez. Proyecto PICT "Prácticas políticas colectivas, modos de gobierno y vida cotidiana: etnografía de la producción de bienes, servicios y cuidados en sectores subalternos", 2016-2019, ANPCyT; Proyecto UBACYT "Etnografía de procesos de organización colectiva del trabajo en sectores subalternos: entre lógicas racionales, prácticas creativas y dinámicas políticas”, programación 2014-2016, ICA, FFYL, UBA. 
entrevistas en profundidad a cuatro de sus miembros fundadores. Para dicha reconstrucción también resultó central el análisis de materiales que habían sido producidos por la propia organización a lo largo del tiempo (videos, producciones radiofónicas, flyers, publicaciones impresas y de difusión).

En primer lugar, presento una aproximación conceptual para analizar tanto las configuraciones urbanas de la desigualdad en la ciudad neoliberal como los procesos de organización que buscaron su transformación. En un segundo momento, muestro el modo en que el Estado y desarrolladores privados transformaron el espacio barrial apoyándose en la estética de ciertas prácticas populares para visibilizar espacios y sentidos de comunidad orientados al turismo, al tiempo que ocultaron otros sujetos, prácticas y formas de vida. A continuación, despliego el modo en que la organización Los Pibes disputó este reparto de lo sensible a partir de la lucha por la vivienda digna y de prácticas de intervención estética en el espacio barrial. Para concluir, propongo una reflexión en torno a la potencialidad de atender a las estéticas (en plural) para la construcción de problemas de investigación y análisis etnográficos.

\section{APUNTES PARA PENSAR LAS LUCHAS EN LA CIUDAD NEOLIBERAL}

Hace más de dos décadas las ciencias sociales han examinado las consecuencias que la globalización y las políticas neoliberales han tenido sobre las ciudades en todo el mundo. Desde la geografía crítica se han producido notables contribuciones que dieron cuenta de las transformaciones socio-espaciales producto de los procesos de "destrucción creativa" desatados conjuntamente por el capital financiero y la gobernanza neoliberal (Brenner y Theodore 2002; Harvey 2013). Una referencia central en este debate ha sido el análisis de David Harvey (2013) sobre el papel activo que desempeña la urbanización en la absorción de los excedentes de capital y en la resolución de las crisis de sobreproducción. Para el autor el alto costo de estos procesos ha sido la desposesión de masas urbanas del derecho a la ciudad y una creciente desigualdad en la distribución de la riqueza con fuertes expresiones en términos espaciales. En esta dirección, un vasto conjunto de investigaciones sobre ciudades en todo el mundo analizó los efectos de la gentrificación y los procesos de segregación como resultado del desarrollo de mega proyectos inmobiliarios, la valorización de los centros urbanos y la privatización de servicios y espacios públicos (Smith 1996; Mitchell 2003; Susser y Schneider 2003; Caldeira 2003; Wacquant 2007; Gledhill 2010; Susser 2012). En particular, algunos autores han señalado la especificidad de estos procesos en las ciudades latinoamericanas destacando que tuvieron como consecuencia el desplazamiento de los sectores populares de los centros urbanos (Carman 2006; Janoschka y Sequera 2016; Zapata, Díaz y Díaz Parra 2018) en articulación con intervenciones políticas higienistas que impusieron un control e invisibilización de 
los usos del espacio considerados indeseables (Díaz Parra y Cuberos Gallardo 2018). ${ }^{4}$

En conjunto, estos estudios han sentado las bases para la reflexión sobre el modo en que estas cambiantes configuraciones urbanas modelaron las formas de organización política urbana en todo el mundo. Así, una importante línea de indagación recuperó la noción de "derecho a la ciudad" propuesta por H. Lefebvre para analizar el modo en que la vida urbana dio impulso a movimientos sociales que luchan por mejores condiciones de vida en las ciudades y por un acceso equitativo a los recursos y servicios que éstas proveen (Gledhill 2010; Harvey 2013; Susser y Tonnelat 2013). En esta dirección, cabe destacar dos etnografías que han abordado desde la categoría de ciudadanía el modo en que las experiencias de vivir en la ciudad modelaron procesos y prácticas políticas urbanas en Latinoamérica. En primer lugar, en su investigación sobre las periferias urbanas en Brasil, James Holston (2008) sostuvo que la experiencia de autoconstruir y vivir en estas periferias se convirtió en el contexto y la sustancia de nuevas formas de "ciudadanía insurgente" a partir de las cuales los pobres urbanos demandaron su membrecía plena a la ciudad y ganaron derechos. Por su parte, la etnografía de Sian Lazar (2013) en la ciudad del Alto, Bolivia, dio cuenta de las múltiples prácticas a través de las cuales los alteños se convirtieron en ciudadanos y constituyeron sujetos políticos colectivos recuperando tradiciones sociales y políticas, pero también a través de experiencias corporales y estéticas en una multiplicidad de espacios urbanos y situaciones: desde fiestas populares, hasta asambleas y movilizaciones.

Más recientemente, algunos autores han explorado el modo en que movimientos de protesta locales recurren a formas de expresión culturales o artísticas para poner en cuestión la configuración espacial de la ciudad neoliberal denunciando creativamente la segregación y desigualdad social (Caldeira 2015; Ufer 2015). Estos trabajos han permitido mostrar el modo en que la ciudad neoliberal es producida de manera disputada no solo por el Estado y los desarrolladores privados, sino también por los movimientos sociales urbanos. Aquí me interesa destacar particularmente una serie de estudios que recuperaron el trabajo de J. Rancière (2014) para abordar la relación entre política y estética en las acciones de dichos movimientos. Estos autores sostuvieron que las formas de intervención visual en el espacio a partir de stencils, graffittis o murales buscan generar conciencia minando la capacidad de creación de consenso de la gubernamentalidad neoliberal (Alexandrakis 2016) y creando espacios para la política que cuestionan las formaciones espaciales actuales y el ideal normativo de la unidad como base de la comunidad política de la ciudad (Arenas 2011).

4 Algunos autores han llegado incluso a poner en tensión la aplicabilidad de la propia categoría de gentrificación desarrollada en la academia anglosajona para el análisis de las dinámicas urbanas en las ciudades latinoamericanas. Para profundizar este debate ver Díaz Parra y Cuberos Gallardo (2018). 
En esta dirección, este artículo recupera la categoría de "reparto de lo sensible" propuesta por Rancière (2014) para reflexionar en torno al modo en que las estéticas trazan los contornos de lo político como forma de experiencia. Desde esta perspectiva, propongo reflexionar sobre las prácticas y experiencias estéticas - definidas en un sentido amplio y sin ser reducidas a lo que comúnmente se considera artístico - como constitutivas de lo político en la medida que intervienen en la delimitación de la experiencia sensible de aquello que es común a la comunidad (Abélès y Badaró 2015). En particular, en este trabajo entiendo a las estéticas como aquello que modela la experiencia sensible y corporal del espacio urbano a partir de sus cualidades visuales, sonoras, olfativas. Además, elijo hablar de estéticas (en plural) para enfatizar que delimitan tanto la manera en que las políticas neoliberales han modelado el espacio barrial, como las formas de intervención y experimentación política que ponen en cuestión dicho ordenamiento sensible. Así busco dar cuenta del carácter disputado de la producción y experiencia sensorial del espacio urbano. Quiero, por un lado, poner de relieve el modo en que para los militantes con quienes trabajé las estéticas fueron una forma de conocer el espacio barrial y sus transformaciones. Al mismo tiempo, analizo las prácticas de producción espacial que desplegaron focalizando en sus cualidades estéticas. En este sentido, quiero dar cuenta de cómo estas intervenciones sobre "el reparto de lo sensible" produjeron una geografía política que inscribió sentidos de comunidad alternativos en el espacio poniendo en cuestión las configuraciones urbanas desiguales.

\section{DE LUCES Y SOMBRAS: RENOVACIÓN URBANA Y ESTÉTICAS POLÍTICAS}

La Boca es uno de los barrios más emblemáticos de la Ciudad Autónoma de Buenos Aires. Está ubicado en su extremo sur y muy próximo a Puerto Madero, un barrio cuyo valor por metro cuadrado construido promedia los 5000 dólares americanos. Separados por tan solo un puente, La Boca presenta una fisonomía bien distinta a los grandes edificios y comercios lujosos que definen aquel barrio vecino. Además, las actuales características de La Boca tienen una larga historia de transformaciones. Hacia fines del siglo XIX, cuando el principal puerto operaba en sus costas, inmigrantes en su mayoría italianos comenzaron a modelar sus actuales características. Así, los conventillos - casas muy coloridas hechas en madera y chapa que se comparten entre varias familias - crearon un escenario urbano característico. Con el cierre del puerto y de las fábricas asentadas en la zona en los años 70, el declive y la degradación de la infraestructura del barrio se aceleraron.

En 1994, cuando los militantes que luego crearon la organización Los Pibes comenzaron sus actividades allí, en La Boca la vivienda era accesible para las familias de sectores populares dada la disponibilidad de múltiples formas de alojamiento a bajo costo, principalmente a través de alquileres de piezas en 
pensiones o conventillos. También había otros modos. Durante mi primera visita a la organización, Lionel me explicó que en el barrio la práctica de "comprar y vender llaves" era sumamente frecuente. Esto implicaba que las familias compraban una llave a una pieza o un pequeño departamento en un conventillo sin saber si el inmueble tenía un propietario legal que luego podría venir a reclamarla.

En virtud de estas condiciones favorables para conseguir un techo donde vivir, en 1994 un grupo de seis familias llegó a La Boca tras haber sido desalojado de su anterior vivienda: las Bodegas Giol en el barrio porteño de Palermo. ${ }^{5}$ Palermo no era cualquier barrio: fue uno de los primeros barrios de la ciudad en evidenciar un proceso de rápido desarrollo urbano que lo convirtió en el segundo más costoso de la capital (después de Puerto Madero). Las bodegas Giol constaban de dos edificios que juntos sumaban casi 10.000 metros cuadrados. Para octubre de 1994, cuando se produjo el desalojo, vivían allí 200 familias y casi 1600 personas (Massetti 2009).

Entre estas familias que llegaron a La Boca estaba la de Martina. Ella se instaló en el conventillo Sancheti junto a su familia. Allí mismo comenzó a juntase a tomar mate con un grupo de militantes que conocía de las Giol, Martín el Oso Cisneros y Lito Borello, quienes tiempo después se convertirían en referentes de la organización Los Pibes. Ambos habían sido parte de la comisión de organización de la asociación civil Familias de la Ex Bodega Giol que impulsó activamente el proceso de organización y la resistencia al desalojo. De aquellas "mateadas" también participan Carolina, Lisando y Lionel, tres estudiantes universitarios que en las Giol habían colaborado haciendo talleres de apoyo escolar para los chicos y organizando eventos culturales.

Para 1996, Martina cedió una pieza de su casa que daba a la calle y allí fundaron el comedor Los Pibes. En aquel momento las tasas de desempleo y pobreza estaban en aumento, ${ }^{6}$ por lo que se abocaron a lo que entendieron como la "necesidad" más urgente: la alimentación. Servían la merienda para los chicos los fines de semana y los feriados porque esos eran los días en los que no la recibían en la escuela. Además, continuaron las reuniones y mateadas con los vecinos del conventillo, a quienes pronto se le sumaron vecinos de casas tomadas, de la villa del bajo autopista y de otros conventillos del barrio. Rita fue una de las primeras en "engancharse" a participar de las reuniones y colaborar con la preparación de la merienda. En 1996 ella también vivía con

5 Un análisis detallado del proceso de ocupación y resistencia al desalojo de las bodegas Giol puede consultarse en Massetti (2009).

6 Entre mayo de 1993 y mayo de 2003 las condiciones de vida de la población se deterioraron de manera creciente. En 1993 el 17,7\% de las personas estaba por debajo de la línea de pobreza, mientras que en mayo de 2003 este indicador alcanzó 60\% de la población. En 2002 se llegó al valor más elevado de desempleo cuando un 21,5\% de la población económicamente activa se encontraba desocupada (Kostzer, Perrot y Villafañe 2005). 
sus cuatro hijos en Sancheti. Todavía recuerda con claridad una cuestión que empezaron a debatir desde aquellas primeras reuniones:

"Y un día de lluvia trajeron el [diario] Clarín. No me voy a olvidar nunca. Lo trajo Lionel. Y ahí decía de los desalojos, cómo se venía La Boca, y ellos nos decían que teníamos que tener una preocupación. Y yo les dije [a los vecinos] tenemos que estar preocupados porque nos van a desalojar, ya hagamos algo."

Por aquellos años, las cosas habían empezado a cambiar vertiginosamente en La Boca. De ser un barrio un tanto olvidado en cuanto a la inversión pública, se convirtió en un sitio de rápido desarrollo urbano. Desde década de 1990 los procesos de gentrificación generaron profundas transformaciones socio-espaciales en la Ciudad Autónoma de Buenos Aires, particularmente en la zona central y sur de la ciudad. En La Boca, una de las primeras intervenciones en esta dirección fue la construcción de defensas costeras, inauguradas en 1998, que mitigaron las inundaciones provocadas por las sudestadas, así como también la remodelación de la ribera para uso recreativo. Al mismo tiempo, comenzaron a instalarse nuevas actividades comerciales y de servicios culturales aprovechando los bajos costos de la propiedad (Herzer et al. 2011). La zona específica que mostró un mayor desarrollo fueron los alrededores de la calle Caminito, una calle peatonal museo franqueada por los tradicionales conventillos restaurados. En su desembocadura en la vera del Riachuelo - área conocida como Vuelta de Rocha - se instalaron museos, restaurantes y pequeños negocios de venta de recuerdos.

Toda esta zona presenta un atractivo visual muy particular. Tal como sostuvo Ana Fabaron, La Boca tiene una larga "tradición de simbolizaciones del barrio" (2016: 71) compuesta de una serie de motivos y elementos simbólicos visuales que se repiten tanto en las prácticas populares de uso de la imagen, como en las intervenciones de renovación urbana que buscan atraer inversiones y consumidores de sectores altos. Los elementos que componen esta tradición barrial y que pueden percibirse en las paredes y la decoración de los comercios son: el Riachuelo, el viejo puente transbordador Nicolás Avellaneda, los conventillos multicolores, el puerto, los colores azul y amarillo del club Boca Juniors, los pintores y artistas, las murgas y el carnaval, el tango (2016). Para la autora estos elementos han sido centrales para la producción de imágenes y escenificaciones comercializables y consumibles.

Así, en La Boca, el proceso de renovación urbana desencadenado se basó en la identidad cultural del barrio para el fomento del turismo. Con María Carman (2006) podemos afirmar que se trató de una "política de lugares" que implicó acciones públicas y privadas sobre espacios locales de la ciudad apelando a la cultura como patrimonio o valor a ser explotado. En otros términos, 
podemos sostener que este desarrollo turístico se apoyó sobre lo que Marc Morell (2015) denominó "trabajo urbano", es decir, sobre formas de vida y construcción popular de la ciudad que fueron explotadas - y expropiadas - por los circuitos de consumo basados en la identidad cultural del barrio. Así, el modo en que el Estado y los desarrolladores privados transformaron el espacio barrial se apoyó en las cualidades estéticas de ciertas prácticas populares para visibilizar espacios y sentidos de comunidad orientados al turismo. Esta estética colorida y alegre busca presentar una comunidad sin conflicto, armónica, ajena a la desigualdad y el padecimiento. Sin embargo, a pocos metros de allí, en las calles no incorporadas en estos circuitos turísticos, la desigualdad se hace palpable y sensible. Desigualdad que se ha visto exacerbada en la medida que este proceso de renovación urbana tuvo un fuerte impacto en las condiciones de vida de los habitantes del barrio.

Entre 1991 y 1996 los precios de la vivienda se dispararon aumentando en un 50\% y los desalojos se convirtieron en una preocupación cotidiana (Herzer et al. 2005). Para los militantes estas transformaciones no pasaban inadvertidas. Lionel me lo explicó en los siguientes términos: "Lo que empezamos a ver es que la estrategia es dejar que algunas partes del barrio se deprecien completamente, no hacer nada, y que luego las empresas de desarrollo inmobiliario y constructoras puedan comprar barato". No estaban equivocados. Tal como señalaron otras investigaciones (Carman 2006; di Virgilio y Guevara 2014) en la Ciudad Autónoma de Buenos Aires las configuraciones urbanas producidas por las políticas neoliberales implicaron la iluminación de determinadas áreas y el ocultamiento de otras, es decir, la conjunción de procesos de reconversión urbana impulsados por el Estado y el sector privado, con la desinversión y el abandono de determinadas zonas.

La organización Los Pibes había nacido justamente en una de esas zonas "ocultas", en uno de los conventillos que no formaba parte de las postales que venden los comercios de recuerdos. Desde allí y junto a los vecinos cuyas condiciones de vida se vieron progresivamente degradadas, en los años 90 iniciaron un proceso de lucha por la vivienda y la mejora de las condiciones del barrio, denunciando lo que definieron como la "expulsión" de los sectores populares. Para ello, conformaron espacios de articulación con otras organizaciones barriales con objetivos e historias similares tales como la "Mesa de Enlace Barrial de La Boca". El efecto de las sostenidas políticas excluyentes en el espacio barrial no hizo más que confirmar sus diagnósticos: un estudio del Área de Estudios Urbanos del Instituto Gino Germani encontró que el 54,5\% de los hogares de bajos ingresos relevados en el año 2000 ya no residían en el barrio diez años después (Herzer et al. 2011).

En efecto, las dos administraciones de Mauricio Macri en la ciudad (2007-2011 y 2011-2015) retomaron y profundizaron este proceso de renovación urbana iniciado por las administraciones previas. Fiel a un modelo de ciudad 
que Adrián Gorelik dio en llamar "ciudad negocio" (2013 [1997]), la administración local puso el suelo urbano al servicio de los desarrollos inmobiliarios. En esta línea se inscribe una particular iniciativa que ha suscitado gran atención: la creación de una serie de "distritos económicos" - denominados del deporte, tecnológico, de las artes, audiovisual y del diseño - que delimitan zonas geográficas dentro de las cuales se incentiva la instalación de empresas de un determinado sector mediante beneficios fiscales y financiamiento estatal. En 2012 se creó el Distrito de las Artes (Ley n. ${ }^{\circ}$ 4353), que abarca el barrio de La Boca y parte de los barrios aledaños de San Telmo y Barracas. Según el gobierno de la Ciudad de Buenos Aires (GCBA), esta iniciativa busca que la zona se convierta en "una zona de atracción turística/cultural ideal para realizar paseos" y "promueve el desarrollo de infraestructura cultural en la zona sur de la ciudad, revitalizando una zona por años postergada".?

Estas intervenciones sobre el espacio delimitaron áreas en función de criterios de mercado y priorizaron las actividades turísticas y comerciales asociadas como prácticas deseables. Esta tendencia se expresó claramente en 2015 cuando el GCBA intentó vender un predio público de tres hectáreas conocido como Casa Amarilla al club Boca Juniors. Allí, el club ampliaría su estadio y, según denunciaron los vecinos, desarrollaría un centro comercial. Sin embargo, el predio era utilizado como área de esparcimiento y para practicar deportes. Por ello, esta venta fue denunciada activamente por un conjunto de organizaciones barriales - entre ellas Los Pibes -, sosteniendo que se trató de una operación fraudulenta que buscaba expropiar para el desarrollo de un negocio privado uno de los pocos espacios verdes públicos disponibles. Al día de hoy esta operación se encuentra judicializada. ${ }^{8}$

Una mañana de 2015 en la esquina de la Covilpi, un militante de Los Pibes y vecino de la cooperativa me comentó que en las calles que rodean al edificio habían hecho el pavimento a nuevo. "Son indicios de que ya vienen por La Boca”, sentenció. Luego me explicó que se comentaba que estaban iniciando con las obras en el Dique 0, una zona que vendría a prolongar las tierras disponibles para Puerto Madero. Agregó que, a cambio de magros subsidios habitacionales del GCBA, varias familias habían abandonado sus casas en el asentamiento del bajo autopista: "Ya tiraron todo abajo... y eran casas de material buenas, sólidas, con baño, todo", se lamentó. Sin embargo, estos cambios que me relataba no eran los únicos "indicios" de las transformaciones que veían ocurrir a su alrededor. En los meses previos, varios me habían comentado que habían visto en la zona propiedades con carteles de venta de la inmobiliaria Adrián Mercado,

7 Información disponible en < http://www.buenosaires.gob.ar/distritodelasartes/que-es > (última consultación en junio 2021).

8 Información disponible en < http://www.paginal2.com.ar/1 13343-a-desalambrar-en-casa-amaril la $>$ (última consultación en junio 2021). 
una inmobiliaria cuya casa central se encuentra nada más ni nada menos que en Puerto Madero. Además, durante una asamblea desarrollada en 2015 un militante comentó que, otra vez, había visto al oficial de justicia que reparte las cédulas de desalojo por las calles cercanas. Estar atentos a estos "indicios" era sin dudas un modo de conocer ese espacio y sus transformaciones. "Interpretarlos políticamente" era la clave para promover la organización de los vecinos.

Estos "indicios" sensibles acabaron siendo confirmados también por otros medios. Desde la multisectorial La Boca Resiste y Propone - un espacio de articulación de organizaciones y militantes barriales del que Los Pibes forma parte - se denunció que desde la creación del Distrito de las Artes los desalojos se incrementaron. Según un relevamiento realizado por ellos mismos, en 2016 se registró la expulsión de 1106 personas y un total de 61 procesos judiciales de desalojos en curso que involucraron a casi 300 familias. A esto se sumó la persistencia de los incendios producidos como consecuencia de las precarias condiciones de los inmuebles. Durante los años que realicé trabajo de campo y recorrí cotidianamente el barrio, me impresionaba - nos impresionaba - el periódico y característico sonido de las autobombas que anunciaba otra tragedia. Estos casos suelen terminar con la expulsión de sus habitantes luego de que el GCBA prohíba el reingreso por riesgo de derrumbe. ${ }^{9}$ Tras el fuego llegan las tapias en puertas y ventanas, marcas que señalan aquellas propiedades desalojadas por el fuego y la justicia, ahora vacías a la espera de ser adquiridas por inversores. Sin embargo, los agentes del avance del negocio inmobiliario no son los únicos que dejaron sus "indicios" o marcas sobre el espacio barrial. Como veremos a continuación, también las organizaciones disputaron este reparto de lo sensible a través de prácticas espaciales y estéticas.

\section{EL BARRIO COMO GEOGRAFÍA POLÍTICA EN DISPUTA}

Tanto en eventos públicos como en intercambios cotidianos, los integrantes de Los Pibes recurrían a la categoría de lucha para referirse a la trayectoria de la organización. Así, el nacimiento de Los Pibes a mediados de los años 90 como un comedor infantil era narrado como una "lucha contra el hambre" para dar respuesta a una "necesidad urgente": la alimentación de sus familias.

9 Vale destacar una serie de casos que, gracias a la organización de las familias y apoyo de organizaciones barriales, se resolvieron de manera beneficiosa para sus habitantes. En este sentido se destaca el caso de la cooperativa Crecer en Ministro Brin conformada tras el dictado de una orden de desalojo para las familias que vivían allí hacía casi 30 años. En noviembre de 2014 un fallo favorable del juez de primera instancia, Caramelo, obligó al Instituto de Vivienda de la Ciudad - organismo local competente en materia de políticas de vivienda - a comprar la propiedad al dueño e inscribirla a nombre de cada uno de los quince socios de la cooperativa. El financiamiento para la compra provino de la Ley n. ${ }^{\circ}$ 341. Más información en < http://www.archivoinfojus.gob.ar/nacionales/cooperativa-de-viviendaya-no-somos-ocupantes-somos-propietarios-6323.html > (última consultación en junio 2021). 
En diversas oportunidades me relataron cómo tiempo después se habían organizado para afrontar desde la lucha otros problemas comunes. Pero, además, esta lucha era cotidianamente puesta en relación con un espacio y una forma de llevarla adelante: "la calle". En la trayectoria de la organización, la calle - y particularmente sitios emblemáticos del barrio como el puente Avellaneda, que conecta La Boca con el vecino municipio de Avellaneda - había sido el sitio del despliegue de numerosos piquetes y ollas populares que quedaron guardados en la memoria de sus integrantes y eran evocados recurrentemente con orgu1lo. ${ }^{10}$ Durante aquella primera visita a la Covilpi, Lionel me introdujo a esta historia vivida: “En el 97' se estaban haciendo ollas populares en las plazas de mayor circulación. Retiro, Constitución, Once... en ese momento nosotros empezamos a hacerlo en el puente Avellaneda". Aquel día recordó particularmente una movilización que hicieron con ayuda del cura de una parroquia del barrio. En aquella oportunidad habían simulado hacer una procesión llevando las imágenes de la iglesia y, con el cura marchando al frente, cortaron el puente. Según me explicó, el objetivo de estas tempranas acciones era protestar por el desempleo y las dificultades para garantizar la subsistencia de las familias, pero la vivienda y los desalojos que afectaban a muchas de las familias que pasaron a integrar la organización también empezaban a perfilarse como una problemática central en el barrio.

A través de la acción directa en las calles que visibilizó sus demandas, lograron que el GCBA aprobara una resolución que declaró emergencia habitacional en el barrio y lo que se conoció como la Operatoria 525. Para quienes integran Los Pibes, se trató de una medida que permitía "frenar los desalojos" que se producían bajo el pretexto de que sus dueños querían vender las propiedades, dando la posibilidad de que las familias compraran sus viviendas a través de créditos otorgados por la Comisión Municipal de la Vivienda de la ciudad (CMV). Rita recuerda claramente los cortes de calle y los reclamos que llevaron a las oficinas públicas para que se aprobara cada crédito. El primero en aprobarse fue para la compra del conventillo donde vivía su hermano. Le siguieron cinco créditos y cinco conventillos más que compraron "como organización" juntando el dinero que se le entregaba a cada familia para realizar la compra colectivamente. ${ }^{11} \mathrm{Al}$ día de hoy Rita vive junto a su familia en uno de los con-

10 Se conoce como piquetes a las cortes de ruta o calles realizados por organizaciones y movimientos sociales desde mediados de los años 90. Dada la recurrencia de esta forma de demanda y protesta que buscaba cortar la circulación para presionar a las autoridades a negociar con los manifestantes a estas organizaciones, se las conoció popularmente como "piqueteras" (Quirós 2011; Manzano 2013). Las ollas populares hacen alusión a la práctica de cocinar en grandes ollas la comida que se comparte entre quienes participan de las acciones de protesta callejeras.

11 Herzer et al. (2011) registraron más de 100 propiedades adquiridas a través de esta operatoria en La Boca y sostuvieron que en todos los procesos hubo una marcada participación de las organizaciones barriales. 
ventillos. Viven en dos departamentos del fondo y al frente funciona la Casa Popular el Patio, un centro cultural sostenido por los propios militantes de Los Pibes bajo su coordinación. En ese mismo espacio a principios de los años 2000 habían creado los primeros "emprendimientos productivos" que dieron trabajo a los integrantes de la organización. Hacían panificados, galletitas y serigrafía, entre otras cosas.

Una de las cuestiones que destacan quienes integran Los Pibes de aquellos años, es que la compra de los conventillos conseguida gracias a la ocupación de "las calles", "mostraba" que era posible conquistar con la lucha la vivienda digna. Así que fueron más allá y comenzaron a participar junto a otras organizaciones - como la Asamblea de Desalojados de La Boca y el Movimiento de Ocupantes e Inquilinos - en la formulación de una ley que les permitiría construir desde los cimientos sus propias viviendas. Esta ley se aprobó como Ley n. ${ }^{\circ} 34 \mathrm{l}$ en el año 2000 y rige en todo el ámbito de la Ciudad Autónoma de Buenos Aires. "La 34l", como se la conoce popularmente, habilitó el acceso a créditos para la adquisición de terrenos y la construcción de obras nuevas o de mejoramiento. A diferencia de políticas habitacionales previas, la ley incorporó no solo a personas individuales como sujeto de crédito, sino también a organizaciones sociales conformadas bajo la figura de cooperativa, mutual o asociación civil para construir a través de la ayuda mutua y autogestión (Thomasz 2008; Zapata 2012).

Fue justamente a través de la Ley n. ${ }^{\circ} 341$ que quienes integran Los Pibes iniciaron la construcción de la Covilpi, un proceso que tomaría más de diez años de lucha. En febrero de 2003 presentaron el proyecto ante la Comisión Municipal de la Vivienda, pero recién escrituraron el terreno en marzo de 2005 y obtuvieron la primera cuota para iniciar la construcción en julio de 2007. La tarea no fue para nada sencilla, tal como me relató Pilar una tarde de 2013 en la que visité la Covilpi. Mientras tomábamos mate en un departamento de la planta baja que se había reservado como espacio común, Pilar me contó que había ingresado a la organización hacia fines de los años 90 cuando vivía junto a su familia en Sancheti. Con tan solo 17 años, acompañaba a su madre al comedor. En el 2013, ella y su marido todavía vivían allí junto a sus seis hijos y estaban a la espera de la inauguración del edificio de la Covilpi para mudarse. Conversamos sobre el avance de la obra y me comentó que estaba muy emocionada de finalmente poder tener su casa: "Si no tenés que vivir alquilando... Y los que más se ponen ansiosos son los chicos viste, siempre me preguntan cuándo van a tener su pieza". "Es una lucha todos los días, una lucha cada día”, concluyó para enfatizar el esfuerzo que implicaba el proceso de construcción del edificio. Esta lucha involucraba tomar turnos para hacer guardias día y noche para evitar ocupaciones y participar de jornadas de trabajo solidario para acelerar la construcción. Pero también requería organizarse para visitar regularmente a los funcionarios del Instituto de Vivienda 
de la Ciudad (organismo que en 2003 reemplazó a la CMV) y de esta manera asegurarse de que sus trámites para recibir los sucesivos desembolsos de fondos "avancen" y que la obra "no se pare".

Aunque a veces algo más lento de lo que esperaban, los trámites y la obra avanzaron. Manuela, hoy vecina de la cooperativa, recuerda que de todo el proceso lo que más la impresionó fue cuando llegaron las "máquinas enormes" que utilizarían para construir los pisos superiores. Lo comparaba con los primeros meses desde la compra del terreno en los que "no había nada, ni cimientos" y dedicaban jornadas enteras a "sacar los yuyos" de un terreno plano y vacío. En marzo de 2015, la Covilpi fue oficialmente inaugurada. Hoy el edificio se eleva como una intervención sobre el espacio urbano que, recuperando las palabras de los cooperativistas mencionadas arriba, "muestra" que la conquista de una vivienda digna es posible. Sus instalaciones nuevas contrastan notoriamente con los conventillos, casas populares y fábricas que la rodean. A su vez, la Covilpi y su materialidad puede ser pensada como una forma de intervención sobre el espacio barrial que muestra el modo en que la organización disputó el "reparto de lo sensible" (Rancière 2014) desde la lucha por la vivienda digna. Pero, al mismo tiempo que evidencia la notoria mejora en las condiciones de vida de quienes lo habitan, también lleva la marca de la estética barrial en sus

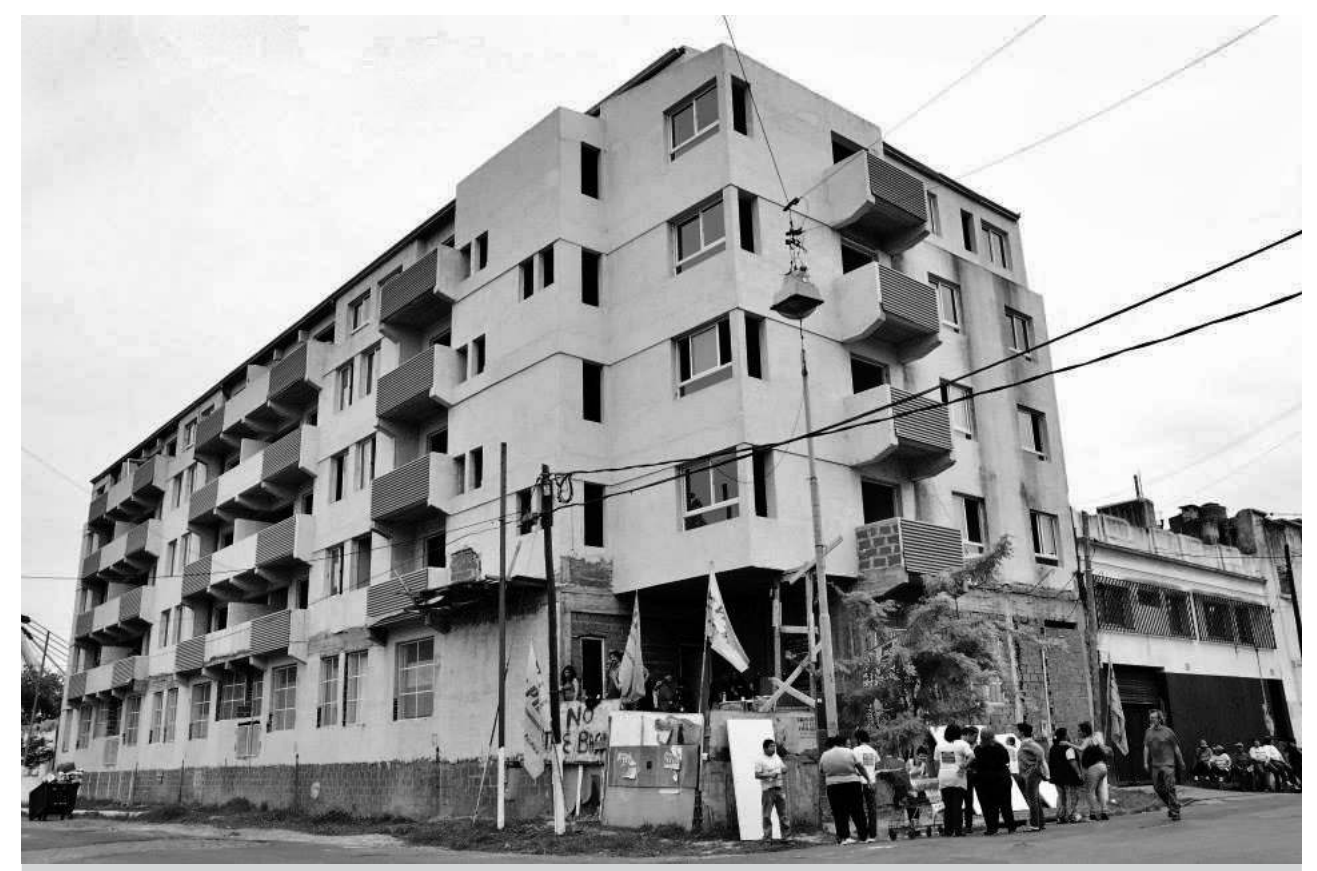

Figura 1 - Frente de Covilpi vista desde las calles Ministro Brin y Lamadrid. Fuente: FM Riachuelo. 
balcones revestidos con las tradicionales y coloridas chapas acanaladas que recubren las fachadas de los conventillos.

En las semanas previas a la inauguración, los cooperativistas fueron poco a poco mudándose al nuevo edificio. De aquellos días, recuerdo preguntar insistentemente cómo se sentían de vivir por fin en sus nuevos departamentos. Las respuestas, que por supuesto enfatizaban la alegría de que la lucha dio sus frutos, incluyeron también comparaciones con sus condiciones de vida previas en los conventillos, comparaciones que anclaban en vivencias profundamente sensibles. Así, por ejemplo, uno de ellos me explicó que le había cambiado la vida porque los conventillos - a falta de ventanas - "son muy oscuros". En el mismo sentido, durante el festejo de inauguración del edificio, el hijo mayor de Rita habló de lo que para él había implicado la mudanza en los siguientes términos:

"Es un sueño, yo vengo de Sancheti, un lugar que está tomado hace 20 años, un lugar donde no había baño, agua potable, gas, donde no venía una asistente social, aislados. Era como que no existíamos. Y eso te hace sentir muy mal porque uno trata de hacer bien las cosas, y el sistema nos cerró, no nos dejó crecer. Hoy en día siento que el comedor, que la organización me dejó crecer, me dejó soñar, me dejó pensar. Estoy re feliz, la verdad que día tras día veo la ventana de mi casa, porque donde vivía no tenía ventanas, y es como ver mi primer televisor. Como sentir que sí formo parte de este mundo, me pase lo que me pase dejarle algo a mis hijos donde van a crecer y van a vivir toda su vida."

Sus palabras inscriben como experiencia personal y sensorial las fracturas y desigualdades inscriptas en el espacio urbano. Pero también señalan el modo en que la disputa por el "reparto de lo sensible" (Rancière 2014) desde la lucha por la vivienda digna habilitó un proceso de politización de la experiencia - sensible, corporal - de vivir en el barrio, proceso que los conformó como colectivo, como organización. Así, la Covilpi, su materialidad y su forma de intervenir en el espacio barrial deja ver, nombrar, y por lo tanto hace "existir", tomando las palabras del hijo de Rita, a aquellos habitantes de sectores populares que no forman parte de la imagen turística de La Boca y que, sin embargo, hace años luchan por permanecer y vivir dignamente allí.

Durante una transmisión radial, uno de los fundadores de Los Pibes se refirió a esta lucha con las siguientes palabras: "Después de pelear por el derecho al laburo y a nosotros poder tener una vivienda nos dimos cuenta que nos nosotros peleábamos por el derecho a poder vivir en la ciudad." En sus propios términos, esta lucha involucraba más que la propia vivienda, o como lo expresaban a menudo en actos públicos: "la lucha no termina con 33 departamentos". En esta dirección, emprendieron otras iniciativas que buscaron 
mejorar las condiciones de vida para el conjunto de los habitantes del barrio. Así, tan solo unos meses después de la inauguración del edificio de Covilpi, la organización puso en marcha una feria popular de alimentos - el Paseo de la Economía Popular Martín Oso Cisneros - en el terreno contiguo a la cooperativa que durante la construcción del edifico había albergado al obrador. La iniciativa llevó ese nombre para recordar al Oso Cisneros, fundador de la organización que fue asesinado en 2004 por un vendedor de droga del barrio. El predio donde se asentó pertenece al GCBA y fue cedido a la organización en comodato por 20 años en 2015. Para los militantes de Los Pibes, esta feria tenía como objetivo principal acercar alimentos de calidad y a bajo costo a los vecinos del barrio. En este sentido, su creación buscaba resistir la degradación de las condiciones de vida para los sectores populares y la privatización de espacios públicos. Esta iniciativa también era cotidianamente relatada como una forma de "ocupar la calle" disputando la organización del territorio barrial frente al avance de los proyectos inmobiliarios. La zona del barrio en la que se encuentra la Covilpi y el terreno donde funciona el mercado es reconocida popularmente como "insegura". En numerosas oportunidades mis interlocutores me comentaron que la custodia policial de los museos de arte cercanos recomendaba a sus visitantes que no se acercaran a ese lado del barrio. Llevar adelante esta feria buscaba transformar el modo en que vecinos - y por qué no los turistas - circulaban por el barrio iluminando las zonas que normalmente se evitaban a partir de la generación de nuevos usos del espacio. Cada fin de semana durante la realización de la feria se desarrollaban además una radio abierta y actividades culturales y recreativas para niños y adultos tales como espectáculos musicales o de títeres. Además, se organizaban visitas guiadas a la Covilpi y encuentros entre cooperativistas y vecinos para transmitir conocimientos y apoyar la conformación de nuevas cooperativas de vivienda. Así, este espacio se convirtió en un sitio clave para sus prácticas de militancia desde dónde promovieron la organización de sus vecinos, mostrando con la materialidad de estas construcciones que disputar y transformar el barrio era posible.

\section{INSCRIBIR HISTORIAS DE LUCHA}

En charlas informales, asambleas, reuniones, Lito Borello - fundador y coordinador de Los Pibes - solía expresar que la militancia involucraba "dar señales", "mostrar caminos posibles" para organizarse y promover que otros los tomen, los copien. En este sentido, la materialidad de aquello que se produjo en el "transcurrir" de su militancia (Fernández Álvarez 2016) - los conventillos comprados, la Covilpi, el Paseo de la economía popular - mostraban esos "caminos posibles". Pero quienes forman parte de la organización también inscribieron mensajes visuales en el espacio barrial a partir de prácticas estéticas como los murales y stencils. En La Boca estas prácticas se inscriben en una 
larga tradición de intervenciones estéticas por parte de numerosos colectivos del barrio como forma de denuncia y protesta (Fabaron 2016). Por ejemplo, en paralelo al aumento de casos de "gatillo fácil" registrados en el barrio en los últimos años, se pueden apreciar en sus calles numerosos murales que lo denuncian. ${ }^{12}$ En ellos se pueden ver los rostros de los jóvenes asesinados por la policía junto a leyendas como "Presente", "Ni un pibe menos" o "Basta de gatillo fácil”.

Hacia 2015, Los Pibes conformó un grupo que dieron en llamar Brigada Comunicacional Martín Oso Cisneros, que no era ni más ni menos que un grupo de militantes abocados a la labor de realizar pintadas y stencils en el barrio. Recuperando el trabajo de Othon Alexandrakis sobre los artistas del graffiti en la Grecia posterior a la crisis de 2010, podemos conceptualizar esta práctica como una forma de "activismo indirecto", una práctica que busca exponer las fracturas sociales señalando alternativas políticas a la gobernanza neoliberal (2016). En el caso analizado por este autor, los activistas buscaban generar una mirada crítica sobre la creciente precariedad de la vida en la ciudad, pero sin recurrir a marcaciones alusivas a una identidad o pertenencia común. En el caso de Los Pibes, en cambio, sus stencils, murales y "pintadas" -frases escritas a pincel sobre paredes blanqueadas con cal - compusieron mensajes que ponían en juego una lectura sobre la historia de la nación y la "Patria grande" latinoamericana, reivindicando ciertas figuras que inspiraban sus ideales de emancipación como el general José de San Martín, Eva Perón o Hugo Chávez.

En su trabajo sobre la organización Túpac Amaru en Argentina, Virginia Manzano (2015) propuso conceptualizar este tipo de prácticas estéticas a través de símbolos e imágenes como formas de ocupar el espacio, de anclar espacialmente tradiciones políticas, sentidos culturales y nociones de bienestar. Las intervenciones de Los Pibes marcaron el espacio barrial recurriendo a figuras-símbolos que remiten a la lectura sobre la historia argentina y latinoamericana que propone la organización. Pero lo que aquí quisiera destacar es que estas figuras-símbolos están asociadas a experiencias históricas o contemporáneas de lucha, asociación que se reforzó a partir de las frases que muchas veces acompañaron las imágenes. El stencil del General San Martín, libertador de América, presentado arriba resulta ilustrativo. El busto ya icónico de este prócer argentino se completó con la sobreimpresión de un pañuelo rojo que cubre su rostro, pañuelo que puede ser asociado al modo en que los manifestantes se cubren el rostro en manisfestaciones callejeras para cubrirse de los gases lacrimógenos utilizados por la policía para reprimir. La frase que completa la composición, "luchar hasta vencer", refuerza la asociación entre las luchas por

12 Se denomina "gatillo fácil" a las muretes, generalmente de jóvenes varones, producidas a manos de las fuerzas de seguridad y en virtud del uso ilegítimo de la fuerza. 

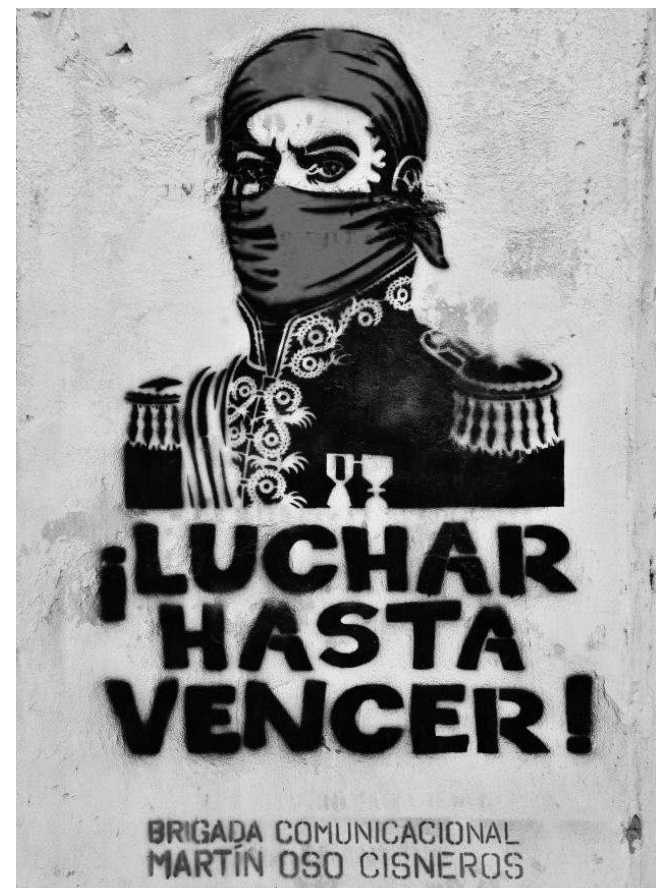

Figura 2 - Stencil del General San Martín realizado en 2013. Fuente: FM Riachuelo.

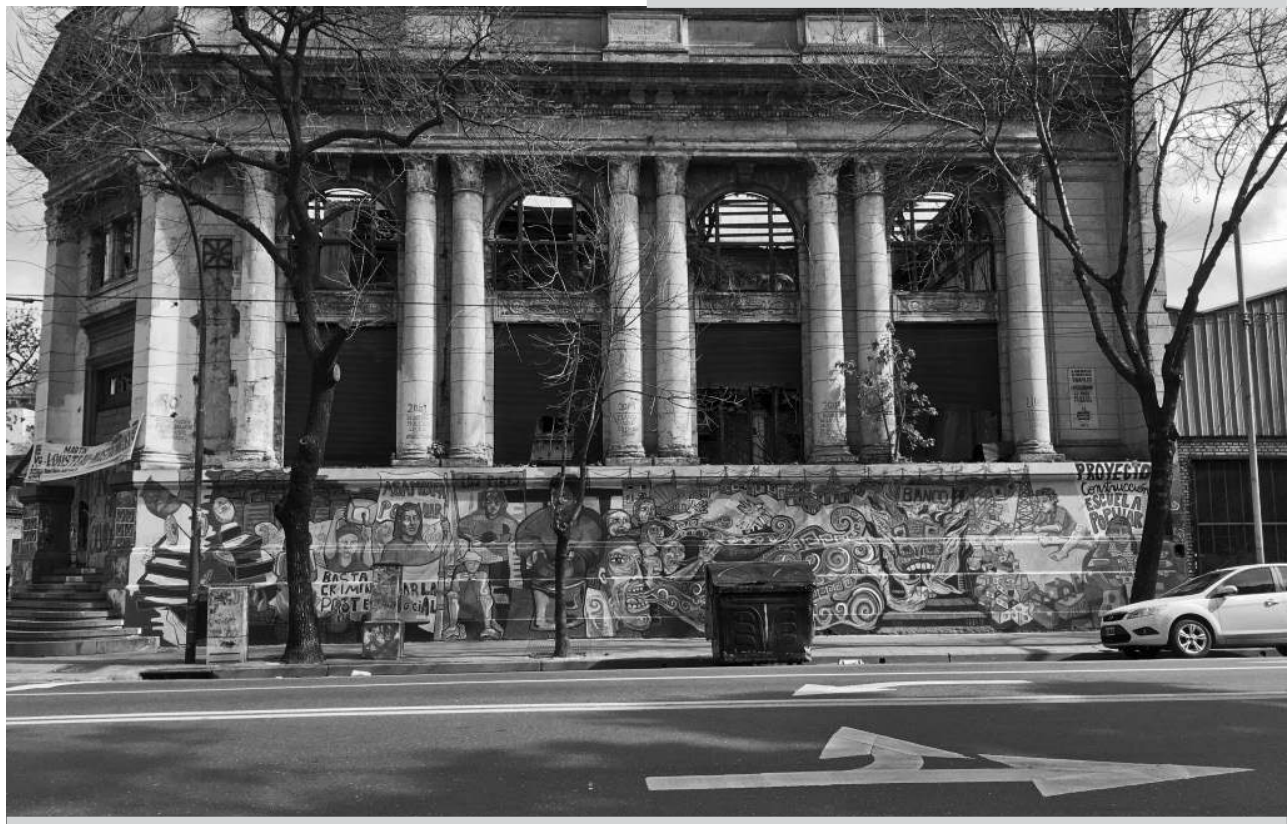

Figura 3 - Plano general del mural realizado sobre la fachada del ex BIRP. Fuente: Archivo personal de la autora. 
la independencia como proyecto inacabado con las luchas desarrolladas en el presente. En este sentido, sus intervenciones disputaron las escenificaciones producidas para el turismo inscribiendo sentidos de comunidad atravesados por la desigualdad, el conflicto y la lucha.

En 2017, junto a un grupo barrial de muralistas intervinieron en un emblemático edificio ubicado justo al lado de la Unidad de Producción Social de Los Pibes. Este edificio había sido una sede del Banco de Italia y Rio de la Plata (BIRP) que, tras ser abandonado, fue ocupado por siete familias. En enero de 2009 se incendió - la causa fue un cortocircuito eléctrico - y seis niños murieron. Todos ellos asistían al comedor de Los Pibes. Su madre, luego del incendio, vivió durante años en un cuarto cedido en uno de los edificios de la organización hasta que volvió a su provincia natal, Entre Ríos. Desde entonces el edificio quedó abandonado a pesar de la presentación de un proyecto de ley en la legislatura para que sea expropiado y se construya un jardín maternal.

Se trata de una ubicación privilegiada para una intervención estética: si bien el cruce de Suárez y Almirante Brown no se encuentra exactamente en la zona preferida por el turismo -Caminito se ubica a unas seis cuadras -, sí se encuentra en el recorrido del bus turístico del GCBA creado bajo la administración de Macri. Sobre su fachada los militantes de Los Pibes habían dibujado otra historia, su historia. Durante años allí se vio un mural de un tren del que

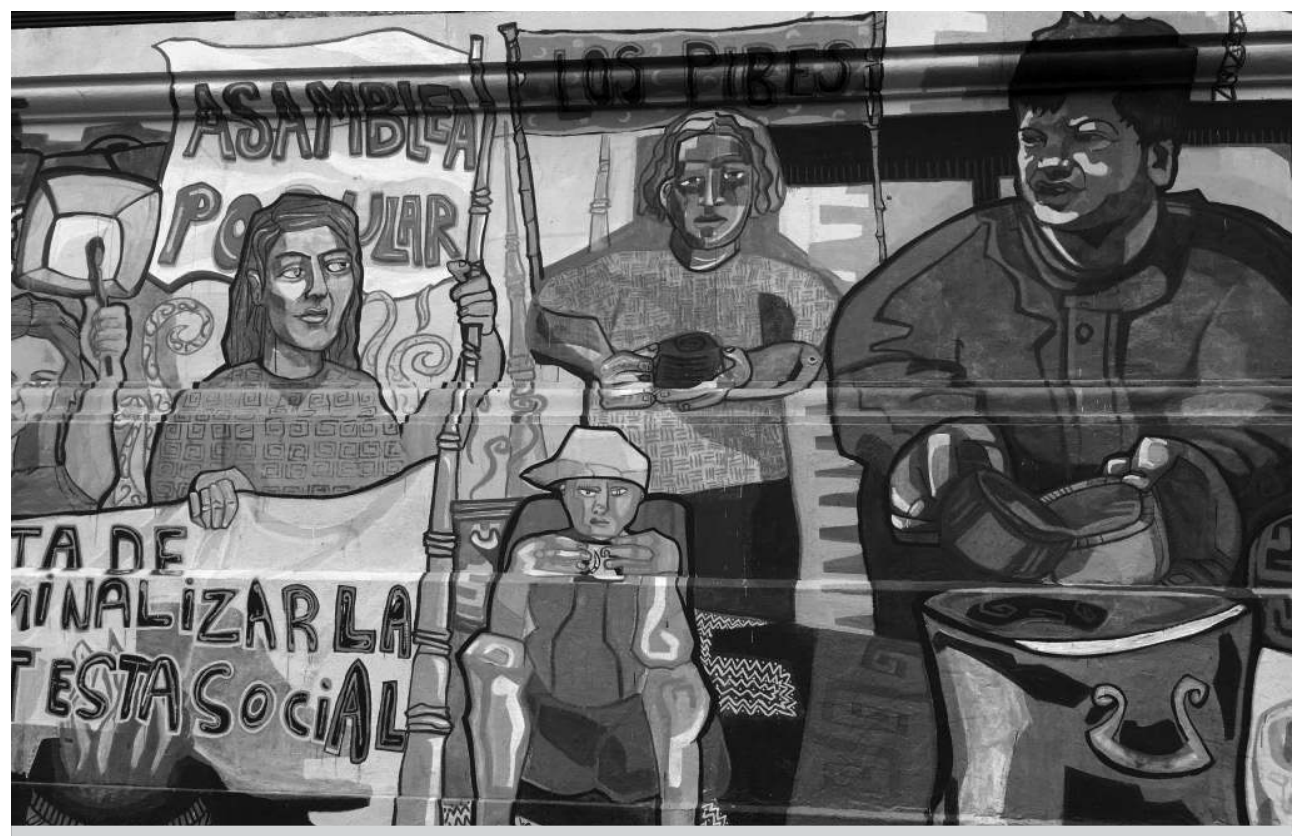

Figura 4 - Detalle del mural realizado sobre la fachada del ex BIRP.

Fuente: Archivo personal de la autora. 
las caras de sus integrantes asomaban por las ventanas y llevaba arriba la inscripción "A 10 años de la rebelión popular 19 y 20 de diciembre", en alusión a las movilizaciones del año 2001 que llevaron a la renuncia del presidente Fernando de la Rúa. Sobre este dibujo ya deteriorado por los años transcurridos, en 2017 pintaron nuevamente su historia, esta vez añadiendo un relato visual de lo que allí había ocurrido. Contrastando con la predominancia del gris y la ruina del fuego que dejó al edificio como un cascarón vacío, cubrieron las paredes con un mural colorido y alegórico. En las escalinatas que llevan hasta la entrada tapiada del edificio, cada escalón lleva el nombre de uno de los niños, sus edades y arriba la inscripción "Nunca más olvidamos". Sobre el lateral, los dibujos muestran el fuego que devoró el edificio, pero también el agua que lo apagó saliendo de la boca de mujeres y hombres con rostros angulosos, expresivos. A un lado, la figura de Martín el Oso Cisneros sirve unos platos de comida de una gran olla popular. Lo rodean sus compañeros, las gomas en llamas que simbolizan el piquete y una leyenda que versa: "Basta de criminalizar la protesta social". Así, este mural denuncia y recuerda los efectos que la gobernanza neoliberal impone sobre los habitantes menos favorecidos, pero también el modo en que sus políticas represivas buscan silenciar y ocultar las acciones y la protesta organizada de los movimientos sociales urbanos.

\section{CONCLUSIONES}

A partir del trabajo etnográfico realizado junto a la organización Los Pibes, en este artículo analicé la producción de una forma de militancia que disputó las configuraciones urbanas de la desigualdad en el barrio de La Boca, Ciudad Autónoma de Buenos Aires. En dicho barrio, los procesos de renovación urbana impulsados por el Estado y desarrolladores privados iluminaron y se apoyaron en las cualidades estéticas de ciertas prácticas y formas de vida popular tales como los conventillos, el fútbol, el tango, etc. Al mismo tiempo, y tal como denunciaron las organizaciones y militantes barriales, estos procesos tendieron a ocultar otros espacios y sujetos, contribuyendo a la creciente segregación y expulsión de los habitantes de bajos recursos. Hemos analizado como en el "transcurrir" de su militancia, la organización Los Pibes disputó este "reparto de lo sensible" (Rancière 2014) a partir de la lucha por la vivienda digna y de prácticas de intervención estética en el espacio barrial.

Para finalizar quisiera proponer una reflexión en torno a la potencialidad de las estéticas (en plural) para la producción de conocimiento etnográfico. Como mencioné al inicio de este trabajo, llegué a la organización interesada por el modo en que organizaciones sociales y políticas desarrollaban actividades de trabajo y productivas. Sin embargo, aprender a ver, escuchar y percibir los "indicios" inscriptos en el espacio urbano - para retomar las palabras de mis interlocutores - me llevó a replantear las preguntas e intereses iniciales de mi 
investigación para incorporar la reflexión sobre el modo en que las dinámicas urbanas modelan y son disputadas por los procesos de militancia. Así, comencé a preguntarme por las formas materiales y sensibles de construir ciudadanía urbana y el "derecho a la ciudad" en contextos particulares. Para responder a esta pregunta, cobró relevancia analítica el modo en que en La Boca el proceso de gentrificación de la zona se apoyó sobre formas de vida y construcción popular de la ciudad que fueron expropiadas por los circuitos de turismo basados en la construcción de una estética "cultural" del barrio. Si esta estética buscó exponer para los consumidores una imagen de una comunidad sin conflicto, sin padecimientos, ajena a la desigualdad, atender a cómo mis interlocutores percibían de manera sensible la materialidad del espacio barrial me mostró aquello que la gobernanza neoliberal busca invisibilizar. Me mostró la experiencia personal y vivida de las fracturas y desigualdades inscriptas en el espacio urbano, pero también el proceso de politizar y convertir esa experiencia personal en una lucha compartida. Esta lucha dejó sus propias marcas espaciales produciendo una geografía política a través de la inscripción de sentidos de comunidad alternativos que recuperaron tradiciones políticas e historias locales, historias a la vez personales y colectivas.

\section{BIBLIOGRAFÍA}

ABÉLÈS, Marc, y Máximo BADARÓ, 2015, Los Encantos del Poder: Desafíos de la Antropología Política. Buenos Aires: Siglo XXI Editores.

ALEXANDRAKIS, Othon, 2016, "Indirect activism: graffiti and political possibility in Athens, Greece", Cultural Anthropology, 31 (2): 272-296.

ARENAS, Ivan, 2011 , Rearticulating the Social: Spatial Practices, Collective Subjects, and Oaxaca's Art of Protest. Berkeley: University of California Press, tesis de doctorado. Disponible en $<$ https://escholarship.org/uc/item/8hm9v2hm > (última consultación en junio 2021).

BRENNER, Neil, y Nik THEODORE, 2002, "Cities and the geographies of 'actually existing neoliberalism" ", Antipode, 34 (3): 349-379.

CAlDeira, Teresa Pires do Rio, 2003, Cidade de Muros: Crime, Segregação e Cidadania em São Paulo. São Paulo: Editora 34.

CALDEIRA, Teresa Pires do Rio, 2015, "Social movements, cultural production and protests: São Paulo's shifting political landscape”, Current Anthropology, 56 (S1 1): S126-S136.

CARMAN, María, 2006, Las Trampas de la Cultura: Los "Intrusos" y los Nuevos Usos del Barrio de Gardel. Buenos Aires: Paidós.

DÍAZ PARRA, Ibán, y Francisco José CUBEROS GALLARDO, 2018, "Políticas de higienización y gentrificación: aportaciones desde el urbanismo latinoamericano", OBJETS, Revista de Ciencias Sociales, 13 (3): 289-316. 
DI VIRGILIO, María Mercedes, y Tomás GUEVARA, 2014, "Gentrificación liderada por el Estado y empresarialismo urbano en la Ciudad Autónoma de Buenos Aires”, Revista Estudios Sociales Contemporáneos, 11: 12-23.

FABARON, Ana, 2016, "Paisajes urbanos, diferencia y desigualdad: el caso de La Boca en Buenos Aires", Revista del Museo de Antropología, 9 (1): 69-82.

FERNÁNDEZ ÁlVAREZ, María Inés, 2016, "Introducción: el desafío de hacer juntos(as)”, in María Inés Fernández Álvarez (coord.), Hacer Juntos(as): Dinámicas, Contornos y Relieves de la Política Colectiva. Buenos Aires: Biblos, $11-30$.

GIROLA, María Florencia, María Paula YACOVINO, y Soledad LABORDE, 2011 , "Recentrando la centralidad: proceso de recualificación urbana y espacio público en la ciudad de Buenos Aires desde una perspectiva etnográfica”, Cuaderno Urbano, 10 (10): 25-40.

GLEDHILL, John, 2010, "El derecho a una vivienda”, Revista de Antropología Social, 19: 103$-129$.

GORELIK, Adrián, 2013 [1997], “Buenos Aires en la encrucijada: modernización y política urbana”, in Adrián Gorelik (coord.), Miradas sobre Buenos Aires: Historia Cultural y Crítica Urbana. Buenos Aires: Siglo XXI, 175-255.

HARVEY, David, 2013, Ciudades Rebeldes. Madrid: Akal.

HERZER, Hilda, Carla RODRíGUEZ, Adriana REDONDO, María Mercedes DI VIRGILIO, y Fernando OSTUNI, 2005, "Organizaciones sociales en el barrio de La Boca: cambios y permanencias en un contexto de crisis”, Estudios Demográficos y Urbanos, 20 (2): 269-308. HERZER, Hilda, María Mercedes DI VIrgilio, Tomás GUEVARA, Julia RAMOS, Pablo VITALE, e Marcelo IMORI, 2011 , "Unos llegan y otros se van: cambios y permanencias en el barrio de La Boca”, Población de Buenos Aires, 8 (14): 7-27.

HOLSTON, James, 2008, Insurgent Citizenship: Disjunctions of Democracy and Modernity in Brazil. Nueva Jersey: Princeton University Press.

JANOSCHKA, Michael, y Jorge SEQUERA, 2016, "Gentrification in Latin America: addressing the politics and geographies of displacement”, Urban Geography, 37 (8): 11 175-1 194. KOSTZER, Daniel, Bárbara PERrot, y Soledad VILlAFAÑe, 2005, Distribución del Ingreso, Pobreza y Crecimiento en la Argentina. Ciudad Autónoma de Buenos Aires: Subsecretaría de Programación Técnica y Estudios Laborales, Ministerio de Trabajo, Empleo y Seguridad Social de la Nación.

LAZAR, Sian, 2013, El Alto, Ciudad Rebelde. La Paz: Plural Ediciones.

MANZANO, Virginia, 2013, La Política en Movimiento: Movilizaciones Colectivas y Políticas Estatales en la Vida Cotidiana del Gran Buenos Aires. Rosario: Prohistoria Ediciones.

MANZANO, Virginia, 2015, "Lugar, trabajo y bienestar: la organización barrial Tupac Amaru en clave de política relacional”, PUBLICAR-En Antropología y Ciencias Sociales, 19 (2015): 9-35.

MASsetTi, Astor, 2009, La Década Piquetera: Acción Colectiva y Protesta Social de los Movimientos Territoriales Urbanos. Buenos Aires: Nueva Trilce.

MITCHELL, Don, 2003, The Right to the City: Social Justice and the Fight for Public Space. Nueva York: Guilford Press.

MORELL, Marc, 2015, "When space draws the line on class", in James Carrier y Don Kalb (coords.), Anthropologies of Class: Power, Practice, and Inequality. Cambridge: Cambridge University Press, 102-117.

QUIRÓS, Julieta, 201 1, El Porqué de los que Van: Peronistas y Piqueteros en el Gran Buenos Aires: Una Antropología de la Política Vivida. Buenos Aires: Antropofagia. 
RANCIÈRE, Jacques, 2014, El Reparto de lo Sensible: Estética y Política. Buenos Aires: Prometeo. SMITH, Neil, 1996, The New Urban Frontier: Gentrification and the Revanchist City. Londres: Routledge.

SUSSER, Ida, 2012, Norman Street: Poverty and Politics in an Urban Neighborhood. Oxford: Oxford University Press.

SUSSER, Ida, y Jane SCHNEIDER, 2003, Wounded Cities: Destruction and Reconstruction in a Globalized World. Nueva York: Berg.

SUSSER, Ida, y Stephane TONNELAT, 2013, "Transformative cities: the three urban commons", Focaal, 2013 (66): 105-121.

THOMASZ, Ana Gretel, 2008, "Historia y etnografía de una normativa polémica: la Ley 341 y el Programa de Autogestión para la Vivienda", Cuadernos de Antropología Social, 28 (2008): 127-149.

UFER, Ulrich, 2015, "Urban access: contested spaces and contested politics", Focaal, 2015 (72): 64-77.

WACQUANT, Loïc, 2007, Los Condenados de la Ciudad: Gueto, Periferias y Estado. Buenos Aires: Siglo XXI.

ZAPATA, María Cecilia, 2012, "Respuesta local a un déficit habitacional local", Astrolabio, 8 (2012): 290-322.

ZAPATA, María Cecilia, Mariela DÍAZ, y Ibán DÍAZ PARRA, 2018, "Presentación del dossier: clases sociales, renovación urbana y gentrificación. Miradas desde América Latina”, Quid, 16 (9): 1-8. 